УДК 581.9: 581.6

DOI 10.30679/2219-5335-2020-5-65-83-99

ПРОИСХОЖДЕНИЕ, РАСПРОСТРАНЕНИЕ И ТАКСОНОМИЯ ДИКОРАСТУЩЕГО ВИНОГРАДА

Гусиев Эмин Кязим оглу аспирант технологического факультета e-mail: emin9415@gmail.com

Исригова Татьяна Александровна д-р с.-х. наук, профессор кафедры товароведения, технологии продуктов и общественного питания e-mail: isrigova@mail.ru

Салманов Мусашейх Мажитович д-р с.-х. наук, профессор зав. кафедрой товароведения, технологии продуктов и общественного питания e-mail:mrksp66@mail.ru

Федеральное государственное бюджетное образовательное учреждение высшего образования "Дагестанский государственный аграрный университет имени М.М. Джамбулатова», Махачкала, Россия

Виноград относится к отряду Rhamnales, семейству Vitaceae или Ampelidaceae, которое делится на два подсемейства: Lecoidaceae и Ampelideae. К последнему подсемейству относится род Vitis. где находится около 40 азиатских видов плюс еще 30 американских, принадлежащих к двум подродам: Muscadinia и Vitis. Считается, что центр разнообразия дикорастущего винограда находится на Ближнем Востоке, от Анатолийского полуострова до Закавказья и Гиркана. Сегодня дикорастущий виноград широко распространен по всей Евразии,

UDC 634.451:634.1

DOI 10.30679/2219-5335-2020-5-65-83-99

\section{ORIGIN, SPREADING AND TAXONOMY OF WILD GRAPES}

Husiyev Emin Kyazim oglu

Post Graduate Student

of Technology Faculty

e-mail: emin9415@gmail.com

Isrigova Tatyana Alexandrovna

Dr. Sci. Agr.,

Professor of Commodity Science,

Food Technology

and Catering Department,

e-mail: isrigova@mail.ru

Salmanov Musasheykh Majitovich

Dr. Sci. Agr., Professor

Head of Commodity Science,

Food Technology

and Catering Department,

e-mail: mrksp66@mail.ru

Federal State Budgetary

Educational Institution

of Higher Education

«Daghestan State

Agrarian University

named after M.M. Dzhambulatov», Makhachkala, Russia

The grapes belong to the order Rhamnales, the family of Vitaceae or Ampelidaceae, which is divided into two subfamilies: Lecoidaceae and Ampelideae. The latter subfamily includes the genus Vitis. where there are about 40 Asian species, plus another 30 American species belonging to two subgenera: Muscadinia and Vitis. It is believed that the center of diversity of wild grapes is located in the Middle East, from the Anatolian Peninsula to Transcaucasia and Hyrcanus. Nowadays, wild grapes are widely spreaded throughout Eurasia, covering 
охватывая территорию от Португалии до Туркменистана, и от берега Рейна до северных лесов Туниса.

В Азербайджане дикий виноград встречается в Самур-Дивичинской и Ленкоранской низменностях, западной и восточной частях Большого Кавказа, северной, центральной и южной частях Малого Кавказа. Филогенетические паттерны предполагают возникновение рода Vitis L. в Северной Америке, фрагментацию предкового ареала в миоцене, образование современных видов в позднем миоцен-плейстоцене и дифференциацию видов в результате плиоцене-четвертичных тектонических и климатических изменений.

О возникновение и развитие дикого винограда в Азербайджане свидетельствуют отпечатки листа дикого винограда Vitis sylvestris Gmel., обнаруженные археологами в верхнем плиоцене на камне у реки Аракс Зангеланского района, вблизи населенного пункта Миндживань на границе с Ираном. Цель работы анализировать данные о происхождении, текущем распространении и таксономии дикорастущего винограда, полученные различными учеными-систематиками и внести ясность в целый ряд дискуссионных вопросов по этому направлению.

Ключевые слова: ДИКОРАСТУЩИЙ ВИНОГРАД, ПРОИСХОЖДЕНИЕ, РАСПРОСТРАНЕНИЕ, ТАКСОНОМИЯ the territory from Portugal to Turkmenistan, and from the banks of the Rhine to the Northern forests of Tunisia. In Azerbaijan, wild grapes are found in the Samur-Divichin and Lankaran lowlands, Western and Eastern parts of the Greater Caucasus, northern, central and southern parts of the Lesser Caucasus. Phylogenetic patterns suggest the emergence of the genus Vitis L. in the North America, the fragmentation of the ancestral area in the Miocene, the formation of modern species in the Late Miocene-Pleistocene and the differentiation of species as a result of Pliocene-Quaternary tectonic and climatic changes. The emergence and development of wild grapes in Azerbaijan is evidenced by the prints of a leaf of wild grape Vitis sylvestris Gmel., discovered by archaeologists in the Upper Pliocene on a stone near the Araks River of the Zangelan Region, near the village of Mindzhivan on the border with Iran. The purpose of this work is to analyze data on the origin, current distribution and taxonomy of wild grapes obtained by various taxonomists and to contribute to a number of discussion issues in this area.

Key words: WILD GRAPES, ORIGIN, DISTRIBUTION, TAXONOMY

Введение. Род Vitis L. (семейство Vitaceae Juss.) насчитывает около 70 древесных лиан, распространенных в основном в умеренных районах Северного полушария $[39,43]$. Из 30 видов, распространенных в Северном полушарии и умеренной и субротпической зонах, на Кавказе и в Азербайджане имеются 3 вида, из них 2 в культуре Vitis labrusca L., V. vinifera L. и один дикорастущий вид Vitis silvestris Gmel. [2]. Vitis silvestris Gmel., именно так дикорастущий виноград был назван Карлом Кристианом Гмелином (немецкий биолог, ботаник и энтомолог), который в 1788 году опублико- 
вал новое издание «Systema Naturae» Линнея, обогатив его множеством дополнений и модификаций. Vitis silvestris Gmel. [47]. - гелиофильная лиана, которая растет в основном вдоль берегов рек, а также в аллювиальных или коллювиальных лиственных лесах $[7,21]$. Ствол растения диаметром до 40 см часто окружает растение, на которое он поднимается.

Дикий виноград - это долгоживущий вид, возраст которого может достигать 300 лет. Кора серовато-бурая, тонкобороздчатая. Листья очередные, в очертании округлые, поперек овальные или почковидные, 5-9 см длиной, 3(5)-лопастные или слабо надрезанные, по краю неравномерно остро зубчатые, с широкой, реже узкой, открытой черешковой вырезкой, большая часть с плоским дном; опушение паутинистое, из щетинистых волосков или смешанное, преимущественно на нижней стороне листа, или листья голые. Цветки двудомные. Тычиночные цветки с длинными тычинками и рудиментарной завязью. У пестичных цветков тычиночные нити короткие, отогнутые в сторону. Соцветия сложные, рыхлые. Грозди во время плодоношения рыхлые, ветвистые, пониклые, 10-15 см длины.

Ягоды дикорастущего винограда в Азербайджане разнообразны: обычно черно-сизые, большая часть шаровидные, с сизым налетом, редко белые, 6-8 (10) мм в диаметре. Кожица плотная с сочной мякотью, обычно кислого вкуса. Семена винограда очень мелкие, яйцевидные, серовато-красноватые, с коротким носиком до 1 мм длины в одном плоде их имеется до 1-4 шт. Цветет виноград с мая до июня, плоды созревают в августе-октябре [2].

Цель работы - проанализировать данные о происхождении, текущем распространении и таксономии дикорастущего винограда, полученные различными учеными-систематиками и внести ясность в целый ряд дискуссионных вопросов по этому направлению.

Происхождение и распространение винограда. Филогенетические паттерны предполагают возникновение рода Vitis L. в Северной Америке, 
Плодоводство и виноградарство Юга России № 65(5), 2020 г.

фрагментацию предкового ареала в миоцене, образование современных видов в позднем миоцен-плейстоцене и дифференциацию видов в результате плиоцене-четвертичных тектонических и климатических изменений [14, 15]. Перос J-P. с соавт. [33] пришли к выводу, что Vitis имеет азиатское происхождение. Окаменелости Vitaceae часто обнаруживались в эоценовых отложениях западной части Северной Америки (55,8-33,9 млн лет назад) и до сих пор не обнаружены в юго-восточных населенных пунктах [24]. Окаменелости семян винограда были найдены в отложениях скалистых гор и равнин Северной Америки $[13,30]$ и в центральной Европе [23, 30]. Эти данные относят возраст винограда к палеоцену (65,5-58,8 млн лет).

В то время суперконтинент Лавразия только начал делиться на Северную Америку и Евразию [34], а в северных широтах климат был значительно теплее [11]. Эти факторы способствовали распространению теплых умеренных наземных организмов в северном полушарии. Nie и соавторы [31] приводят доводы в пользу североамериканского происхождения Vitaceae. Молекулярный филогенетический анализ нескольких непересекающихся родов показал прогрессию распространения дикой виноградной лозы из Восточной Азии в Восточную и Западную Северную Америку [40, 42]. Таким образом, анализ литературных данных подтверждает выводы о происхождении самого последнего общего предка Vitis в Северной Америке.

О возникновении и развитии дикого винограда в Азербайджане свидетельствуют отпечатки листа дикого винограда Vitis sylvestris Gmel., обнаруженные археологами в верхнем плиоцене на камне у реки Аракс Зангеланского района, вблизи населенного пункта Миндживань на границе с Ираном [1].

Сегодня дикорастущий виноград широко распространен по всей Евразии, охватывая территорию от Португалии до Туркменистана, и от берега Рейна до северных лесов Туниса [39]. В Азербайджане дикий вино- 
град встречается в Самур-Дивичинской и Ленкоранской низменностях, западной и восточной частях Большого Кавказа, северной, центральной и южной частях Малого Кавказа от низменности до нижнего, реже среднего горного пояса. Чаще всего произрастает в пойменных, приречных, низовых лесах, в качестве лианы и кустарниковых зарослей [2].

Считается, что центр разнообразия дикорастущего винограда находится на Ближнем Востоке, от Анатолийского полуострова до Закавказья и Гиркана [19], где до сих пор существуют самые древние евразийские виды рода Vitis [43]. К сожалению, точное время и место одомашнивания винограда в Западной Азии неизвестно из-за неполноты археоботанических и палинологических данных из данного региона. Считается, что одомашнивание и посадка виноградников восходит к раннему бронзовому веку [26]. Макговерн предположил, что люди впервые одомашнили дикий виноград в высокогорных районах восточной Турции и на северо-западе Ирана между 6000 и 8000 гг. до н.э. [25]. От третичного периода до сегодняшнего дня на распространение дикого винограда оказали влияние климатические силы, воздействие человека и распространение патогенных микроорганизмов. На сегодняшний день по причине антропогенного воздействия, природных явлений, таких как наводнения и пожары, а также появления плесневых болезней и филлоксеры в Европе, V. vinifera ssp. sylvestris является видом, находящимся под угрозой исчезновения $[6,7]$.

Процессы выращивания и одомашнивания винограда по-видимому, происходили между седьмым и четвертым тысячелетием до нашей эры в южной части Кавказа, в частности, в географическом районе между Черным морем и Каспийском морем [45]. Эта область, возможно, была основным центром одомашнивания $[8,9,20]$. Фактически из этой зоны культивируемые формы распространялись людьми на Ближнем Востоке, Среднем Востоке и в Центральной Европе (рис. 1). 


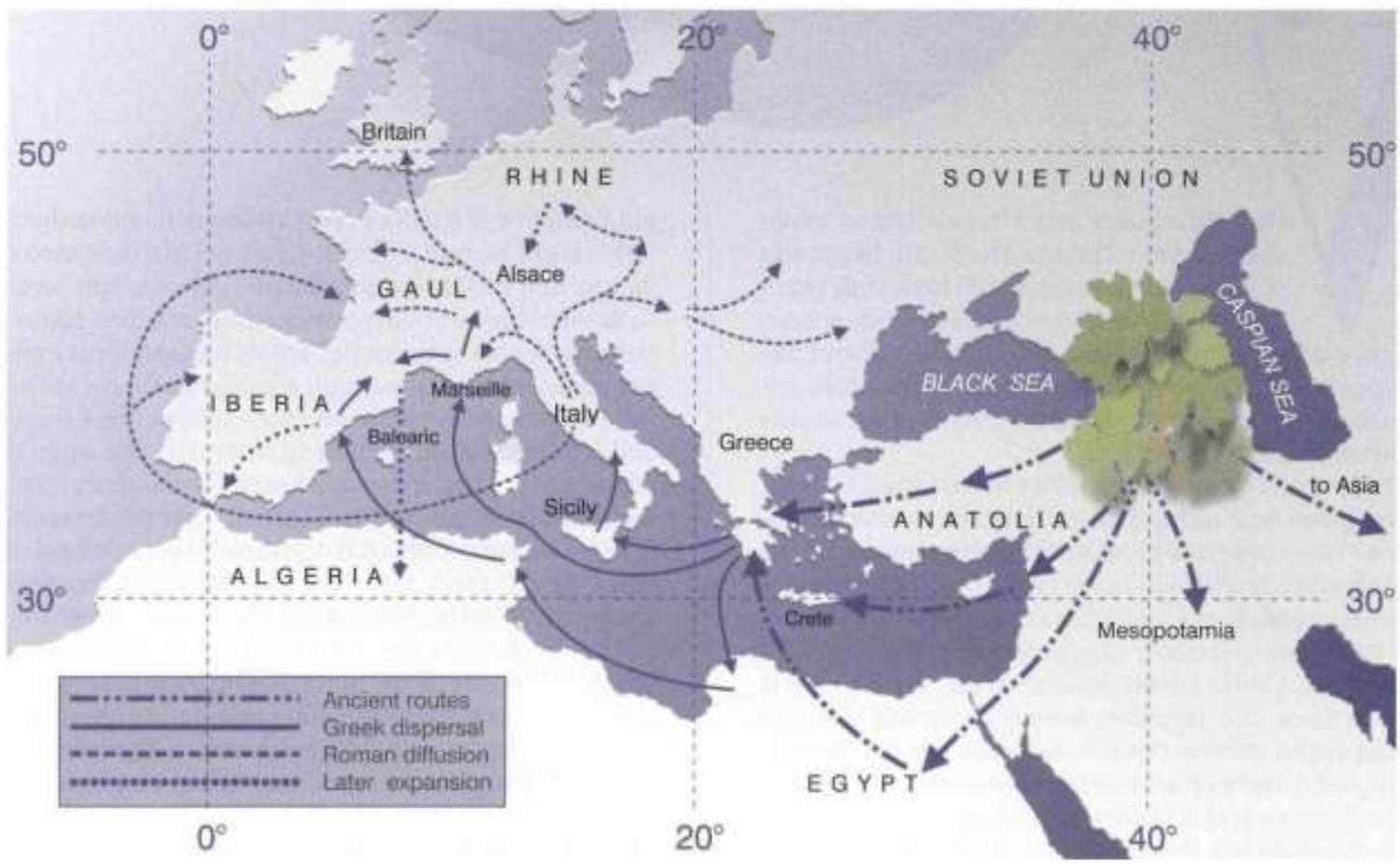

Рис.1. Основные пути виноградарства от Кавказа до Европы [18].

Дикие винограды (Vitis vinifera subsp. sylvestris) были в изобилии в их ареале обитания в Европе до середины девятнадцатого века, когда прибытие иностранных вредителей, таких как филлоксера (Daktulosphaira vitifoliae), и разрушение их мест обитания, вызванное урбанизацией и интенсификацией сельского хозяйства, увеличили риск потери европейских диких виноградов [32].

Процесс одомашнивания винограда включал отбор той небольшой части генотипов гермафродитов, которая дает более крупные и более сладкие ягоды привлекательных цветов, и разработку методов их вегетативного размножения [45]. Винограды выращивались в Греции со второго тысячелетия до нашей эры, и благодаря финикийской и греческой колонизации они были экспортированы в другие европейские регионы, после чего последовало распространение знаний о виноградарстве. После этого римляне стали послами виноградарства, и в связи с переходом в христианскую веру пить вино стало частью европейской культуры.

Естественное присутствие диких видов и на территории Азербайджана от 18 м ниже уровня моря (побережье реки Куры в Сальянском рай- 
оне) до 2000 м выше уровня моря (Кусарский район) [1] позволяет предполагать, что одомашненные винограды были вегетативно размножены людьми бронзового века именно в Каспийском регионе.

Агробиологической и химико-технологической оценкой столовых сортов винограда в условиях укрывной зоны Дагестана занимаются ученые на кафедре товароведения, технологии продуктов и общественного питания Дагестанского государственного аграрного университета [51-54], также ими изучается качество столовых сортов винограда и разрабатываются технологии производства из винограда продуктов повышенной пищевой ценности [48-50].

Таксономический статус и внутривидовая дифференциация. На сегодняшний день классификация Vitis запутана из-за отсутствия согласия среди систематиков в связи с огромными морфологическими изменениями в пределах вида $[4,15,35]$. Это привело к путанице в названии видов [36]. Систематика Vitis основана главным образом на морфологии [10], и молекулярные методы только лишь недавно были использованы для изучения этой таксономической проблемы.

Виноград относится к отряду Rhamnales, семейству Vitaceae или Ampelidaceae, которое делится на два подсемейства: Lecoidaceae и Ampelideae. К последнему относится род Vitis и другие четыре рода, используемые в декоративных целях. В роде Vitis находится около 40 азиатских видов плюс еще 30 американских, принадлежащих к двум подродам: Muscadinia и Vitis (рис. 2). Все эти виды, как правило, интерфертильные и диплоидные $(2 \mathrm{n}=38)$, за исключением подрода Muscadinia, которая включает Vitis rotundifolia c $2 \mathrm{n}=40$.

Среди группы европейско-азиатских виноградов, характерных для умеренного климата, обнаруживается Vitis vinifera, который включает в себя 2 подвида: $V$. v. sylvestris, и $V$. v. sativa (рис. 2). 


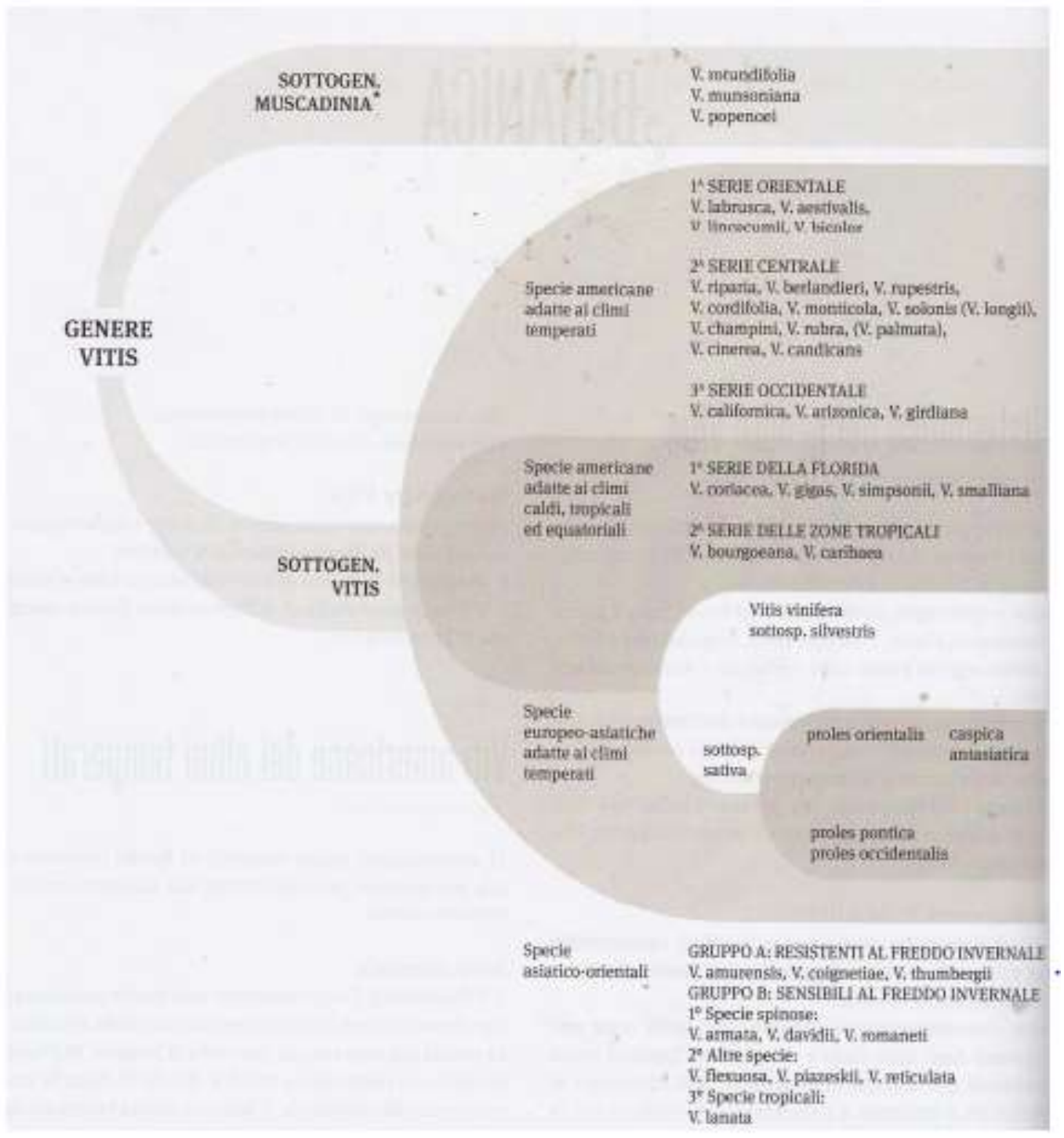

Рис. 2. Классификация рода Vitis [18].

Подавляющее большинство сортов, в настоящее время широко выращиваемых для получения плодов, соков и главным образом вина, классифицируется как Vitis vinifera L. subsp. vinifera (или sativa), происходят от диких форм [Vitis vinifera L. subsp. sylvestris (Gmelin) Hegi] [38, 39]. Подрод Muscadinia состоит только из 2-3 видов из США, Западной Индии и Мексики [12], тогда как подрод Vitis имеет широкое распространение в северном полушарии. Все виды двудомные, кроме V. vinifera, которая имеет гермафродитные цветки. Многие виды имеют пересекающееся распределение, поэтому естественная гибридизация могла бы произойти, если бы не экологические и фенологические барьеры $[14,15,28]$. Кроме того, меж- 
Плодоводство и виноградарство Юга России № 65(5), 2020 г.

ду диким и культивируемым виноградом был возможен умеренный или высокий поток генов $[17,22]$.

Дикорастущий виноград - полиморфный вид. Существуют серьезные расхождения между разными авторами относительно его правильной таксономии. Размножение семенами в прошлом привело к созданию большого числа генотипов, которые распространились по широкому кругу почв и климатических сред, накапливая многочисленные мутации и, таким образом, увеличивая генетическую изменчивость популяций. К этому следует добавить большую адаптивность растения, которое меняет свой внешний вид в зависимости от условий окружающей среды.

На генетическом уровне, а также с точки зрения ампелографии, два подвида $V$. vinifera связаны, но расходятся [44]. В то время как некоторые считают, что $V$. v. vinifera L. и V. v. sylvestris (Gmelin) разделены, другие полагают, что дифференциация не идет дальше уровня подвида. Согласно последним, эти дикие винограды не представляют собой отдельный вид или даже подвид, а представляют собой группу генотипов в Vitis vinifera L., которые развиваются в диком состоянии.

Очень важно подчеркнуть наиболее важные различия, которые позволяют отличать культивируемый виноград (с его многочисленными сортами и разнообразием, даже клональными) от дикого винограда. Принципиальные отличия между ними следующие:1) наличие мужских и отдельных женских растений в диких популяциях, хотя цветки морфологически гермафродитные, на самом деле они двудомные и нуждаются в перекрестном оплодотворении; даже если возможно существование гермафродитных растений, но они не превышают 5 \% от общей численности популяции [5], напротив, культивируемые сорта являются гермафродитами и имеют возможность самооплодотворения; 2) у диких виноградов кончик молодого побега всегда открыт; 3) размер ягод и гроздей дикорастущего винограда меньше, чем у культивируемого, а также плотность гроздей очень рыхлая; 
4) существуют различия в размере и форме семян: в диком винограде они меньше и округлены; размер и форма семян V. v. sylvestris являются определяющим фактором по самой их идентификации и, в частности, по соотношению размера/длины [21]; 5) среди диких виноградов наблюдается диморфизм листьев: лист у мужского растения больше прорезан с извилистыми лопастями, тогда как у женского растения они цельные, немного лопастные с коротким стеблем.

На сегодняшний день в Международном индексе названий растений [46] дикорастущий виноград рассматривается в качестве подвида вида V. vinifera - Vitis vinifera subsp. Sylvestris Willd. (= V. gmelinii Buttler), хотя долгое время в азербайджанской, иранской и других флорах он считался отдельным видом - V. sylvestris Gmel. [3, 27, 41]. Во флоре же СССР вид долгое время находился под названием V. hyrcanica Vass [3] и лишь позже был синонимизирован с V. sylvestris [41].

Основываясь на различиях волосяного покрова нижней поверхности листьев винограда из северной и восточной частей Ирана, в рамках таксона были предложены два подвида (V. sylvestris subsp. anebophylla Kolen. и subsp. trichophylla Kolen.) [41]. Было выявлено, что нижняя часть листа подвида anebophylla Kolen. была покрыта длинными арахноидальными, отжатыми волосками (трихомами), которые выпадают в конце вегетации, в то время как в подвиде trichophylla, нижние части были покрыты мелкими клеточными волосками [41]. Наличие двух разных таксонов в группе $V$. sylvestris не было описано в других местах произрастания винограда. Однако Vitis trichophylla (Kolen.) Vass. был предложен как отдельный вид во флоре СССР среди 12 видов $V$. vinifera sensu lato [3].

Это историческое разделение на виды и подвиды было основано на морфологических различиях. Полученные в исследованиях This P. с соавторами результаты относительно V. sylvestris были неожиданными. По их результатам, V. sylvestris является предполагаемым прародителем V. vinif- 
era [39], в то время как филогенетическая позиция предполагает, что $V$. sylvestris был получен из V. vinifera. Эволюция задерживается клональным размножением, в результате чего дикорастущие виды естественным образом выглядят больше производными.

Myles et al. [29] пришли к выводу, что современные коммерческие copта $V$. vinifera только на один или два поколения удалены от дикого $V . s y l$ vestris. Во время одомашнивания произошли многочисленные изменения в биологии вида, которые привели к увеличению содержания сахара в ягодах и более регулярному плодоношению. В ходе этого процесса как вегетативные (размеры ветвей), так и репродуктивные части растения (морфология семян и переход от двудомных диких растений к гермафродитным культивируемым растениям) претерпели существенные изменения [39].

Заключение. Vitaceae - семейство, которое содержит два подсемейства: Lecoidaceae u Ampelideae. К последнему относится род Vitis, содержащий два подрода: Muscadinia и Vitis. Подрод Vitis включает в себя 2 подвида: Vitis vinifera L. subsp. vinifera (или sativa), и дикий виноград - Vitis vinifera L. subsp. sylvestris Gmel. На генетическом уровне, а также с точки зрения ампелографии, два подвида $V$. vinifera связаны, но расходятся. Выявлено, что возникновение рода Vitis L. берет свое начало в Северной Америке, центр же разнообразия дикорастущего винограда находится на Ближнем Востоке, от Анатолийского полуострова до Закавказья и Гиркана.

Молекулярно-филогенетический анализ нескольких непересекающихся родов показал прогрессию распространения рода Vitis L. из Восточной Азии в Восточную и Западную Северную Америку. Сегодня дикорастущие виноградные лозы широко распространены по всей Евразии, охватывая территорию от Португалии до Туркменистана, и от берега Рейна до северных лесов Туниса. Отпечатки листа дикого винограда Vitis sylvestris Gmel., обнаруженные археологами в верхнем плиоцене на камне у реки 
Плодоводство и виноградарство Юга России № 65(5), 2020 г.

Аракс Зангеланского района, вблизи населенного пункта Миндживань на границе с Ираном, свидетельствуют о возникновении и развитии дикого винограда в Азербайджане.

\section{Литература}

1. Аманов М.В. Дикорастущий виноград Азербайджана // Политематический сетевой электронный научный журнал Кубанского государственного аграрного университета (Научный журнал КубГАУ) [Электронный ресурс]. 2006. №02(18). С. 152-161. Шифр Информрегистра: $042060001210034 . \quad$ Режим доступа: http://ej.kubagro.ru/2006/02/pdf/16.pdf, 0,625 у.п.л.

2. Прилипко Л.И. Виноградовые - Vitaceae Lindl. Флора Азербайджана. Т. 6. Баку, 1955. С. 203-208.

3. Сосновский Д.Н. Виноградовые - Vitaceae Juss. Флора СССР. Т. 14. М.; Л., 1949. C. 674-710.

4. Alleweldt G., Spiegel-Roy P., Reisch B.: Grapes (Vitis). Genetic resources of temperate fruit and nut crops // Edited by: Moore J.N., Ballington J.R. Acta Hort. 1990. Vol. 290. P. 291-337.

5. Anzani R., Failla O., Scienza A., De Micheli L. Individuazione e conservazione del germoplasma di vite selvatica (Vitis vinifera sylvestris) in Italia // Vignevini. 1993. Vol. 6. P. 51-61.

6. Arnold C. Ecologie de la vigne sauvage, Vitis vinifera L. ssp. sylvestris (Gmelin) Hegi, dans les forêts alluvoales et colluviales dËurope // Geobotanica Helvetica. Academie Suisse des Sciences Naturelles. 2002.

7. Arnold C., Gillet F., Gobat J.M. Situation de la vigne sauvage Vitis vinifera ssp. sylvestris en Europe. Vitis. // 1998. № 41. P. 159-170.

8. Arroyo-garcìa R., Ruiz-garcìa L. Bolling L., Ocete L., Lòpez M. A., Arnold C., Ergul A. Multiple origins of cultivated grapevine (Vitis vinifera L. ssp. sativa) based on chloroplast DNA polymorphisms // Molecular Ecology. 2006. №15. P. 3707-3714.

9. Bacilieri R., Lacombe T., Le Cunff F., Di Vecchi-staraz M., Laucou V., Genna B., Peros J. P., This P., Boursiquot J. M. Genetic structure in cultivated grapevines is linked to geography and human selection. BMC Plant Biology. 2013. Vol. 13. P. 25.

10. Barrett H.C., Cramer S.G., Rhodes A.M. A taximetric study of interspecific variation in Vitis // Vitis. 1969. № 8. P. 177-187.

11. Bowen G.J., Beerling D.J., Koch P.L., Zachos J.C., Quattlebaum T. A humid climate state during the Palaeocene/Eocene thermal maximum // Nature. 2004. Vol. 432. P. 495-499.

12. Brizicky G. K. The genera of Vitaceae in the southeastern United States // Journal of the Arnold Arboretum. 1965. 4.

13. Brown R.W. Paleocene flora of the Rocky Mountains and Great Plains // US Geol Surv Prof Pap. 1962. Vol. 375. P. 1-120.

14. Comeaux B.L. Taxonomic studies on certain native grapes of the Eastern United States. PhD thesis. North Carolina State University: Department of Horticultural Science. 1984.

15. Comeaux B.L., Nesbitt W.B., Fantz P.R. Taxonomy of the native grapes of North Carolina // Castanea. 1987. Vol. 52: 197-215.

16. Cunha J., Baleiras-Couto M., Cunha J. P., Banza J., Soveral A. Carneiro L. C., Eiras-Dias J. E. Characterization of Portuguese populations of Vitis vinifera L. ssp. sylvestris (Gmelin) Hegi // Genet. Resour. Crop. Evol. 2007. Vol. 54. P. 981-988. 
17. Di Vecchi-Staraz M., Laucou V., Bruno G., Lacombe T., Gerber S., Bourse T, et al. Low level of pollen-mediated gene flow from cultivated to wild grapevine: consequences for the evolution of the endangered subspecies Vitis vinifera L. ssp. Sylvestris // J Hered. 2009. Vol. 100. P. 66-75.

18. Fregoni M. Viticoltura di Qualità - Trattato dell'eccellenza da terroir. III edizione. Ed. Tecniche nuove. 2013.

19. Grassi F., De Mattia F., Zecca G., Sala F., Labra M. Historical isolation and Quaternary range expansion of divergent lineages in wild grapevine // Biol J Linn Soc. 2008. Vol. 95. P. 611-616.

20. Grassi F., Labra M., Imazio S., Spada A., Sgorbati S., Scienza A., Sala F. Evidence of a secondary grapevine domestication centre detected by SSR analysis // Theoretical and Applied Genetics. 2003. Vol. 107. P. 1315-1320.

21. Levadoux L. Les populations sauvages de Vitis vinifera L. // Ann. Amel. Plantes. 1956. Vol. 6. P. 59-118.

22. Lopes M.S., Mendonca D., Rodrigues dos Santos J.E., Eiras-Dias J.E, Da Camara Machado A. New insights on the genetic basis of Portuguese grapevine and on grapevine domestication // Genome. 2009. Vol. 52. P. 790-800.

23. Mai D.H. Neue früchte und samen aus Paläozänen ablagerungen Mitteleuropas // Feddes Repertorium. 1987. Vol. 98. P. 197-229.

24. Manchester S.R. Biogeographical relationships of North American Tertiary floras // Ann Missouri Bot Gard. 1999. Vol. 86. P. 472-522.

25. Mc Govern P.E. Ancient wine: The search of the origin of the viniculture. Princeton Univ. Press. 2003.

26. Miller N.F. Sweeter than wine? The use of the grapevine in early western Asia. Antiquity. 2008. Vol. 82. P. 937-946.

27. Mozaffarian V. Trees and shrubs of Iran. Farhang Moaser Publishers, Tehran. 2005. 1054 p.

28. Mullins M.G., Bouquet A., Williams L.E. The grapevine and its relatives. Biology of the grapevine. Edited by: Mullins MG, Bouquet A, Williams LE. Cambridge: Cambridge University Press. 1992. P. 17-36.

29. Myles S., Boyko A.R., Owens C., Brown P.J., Grassi F., Aradhya M.K., Prins B., Reynolds A., Chia J-M., Ware D., Bustamante C.D., Buckler E.S. Genetic structure and domestication history of the grape // Proc Natl Acad Sci. 2011. Vol. 108. P. 3530-3535.

30. Nie Z-L., Sun H., Chen Z-D., Meng Y., Manchester S.R., Wen J. Molecular phylogeny and biogeographic diversification of Parthenocissus (Vitaceae) disjunct between Asia and North America. Am J Bot. 2010. 97. P. 1342-1353.

31. Nie Z-L., Sun H., Manchester S.R., Meng Y., Luke Q., Wen J. Evolution of the intercontinental disjunctions in six continents in the Ampelopsis clade of the grape family (Vitaceae). BMC Evol Biol. 2012. P. 212.

32. Ocete R., Ocete R., Ocete C., Angeles Perez Izquierdo M., Rustioni L., Failla O., Chipashvili R., Maghradze D. Ecological and sanitary characteristics of the Eurasian wild grapevine (Vitis vinifera L. ssp. sylvestris (Gmelin) Hegi) in Georgia (Caucasian region) // Plant Genetic Resources: Characterisation and Utilisation. 2012. Vol. 10. Issue 2. P. 155-162.

33. Péros J-P., Berger G., Portemont A., Boursiquot J-M., Lacomb T. (2011) Genetic variation and biogeography of the disjunct Vitis subg. Vitis (Vitaceae) // J Biogeogr. 2011. Vol. 38. P. 471-486.

34. Press F., Siever R. New York: W.H. Freeman and Company. 1985. 4

35. Reisch B.I., Pratt C. Grapes. Fruit breeding. Edited by: Janick J, Moore JN. New York: Wiley. 1996. P. 297-369. 
36. Rogers D.J., Rogers C.F. Systematics of North American grape species // Am J Enol Vitic. 1978. Vol. 29. P. 73-78.

37. Sabeti H. Forests, trees, and shrubs of Iran, vol 13. University of Yazd Press, Yazd. 1976. P. 1-886 (in Persian).

38. Sefc K. M., Steinkellner H., Lefort F., Botta R., Camara Machado A., Borrego J., Maleti E., Glossl J. Evaluation of the genetic contribution of local wild vines to European germplasm // Am. J. Enol. Vitic. 2003. Vol. 54. P. 15-21.

39. This P., Lacombe T., Thomas M.R. Historical origins and genetic diversity of wine grapevines // Trends Genet. 2006. Vol. 22. P. 511-519.

40. Tiffney B.H., Manchester S.R. The use of geological and paleontological evidence in evaluating plant phylogeographic hypotheses in the northern hemisphere Tertiary // Int J Plant Sci. 2001. Vol. 162 (Suppl 6). P. 3-17.

41. Vassilczenko L.T. Vitaceae. In: Rechinger KH (ed) Flora Iranica, vol 74. Academische Druck Verlagsanstalt, Graz. 1970. P. 1-5 (in Persian).

42. Xiang Q-Y., Soltis D.E., Soltis P.S. The Eastern Asian and Eastern and Western North American floristic disjunction: congruent phylogenetic patterns in seven diverse genera // Mol Phylogenet Evol. 1998. Vol. 10. P. 178-190.

43. Zecca G., Abbott J.R., Sun W.B., Spada A., Sala F., Grassi F. The timing and the mode of evolution of wild grapevines (Vitis). Mol Phylogenet Evol. 2012. Vol. 62. P. 736-747.

44. Zecca G., De Mattia F., Lovicu G., Labra M., Sala F., Grassi F. Wild grapevine: silvestris, hybrids or cultivars that escape from vineyards? Molecular evidence in Sardinia // Plant Biology. 2010. Vol. 12. P. 558-562.

45. Zohary D. Domestication of the grapevine Vitis vinifera L. in the Near East. In: Mc Govern P. E. (Ed.), The Origins and Ancient History of Wine. Gordon and Breach, Philadelphia. 1995. P. 23-30.

46. https://www.ipni.org/n/69086-1

47. http://www.theplantlist.org/tpl1.1/record/kew-2456987

48. Исригова Т.А., Мусаева Н.М., Салманов М.М. Биологически активные добавки из семян, кожицы и гребней винограда // Проблемы развития АПК региона. 2012. Т. 10. № 2 (10). С. 113-119.

49. Способ консервирования плодов и ягод: патент на изобретение RUS 2347505 / Исригова Т.А., Салманов М.М.; заявл.13.08.2007, опубл. 2009-02-27.

50. Исригова Т.А., Салманов М.М., Багавдинова Л.Б. Производство функциональных безалкогольных напитков на основе винограда // Проблемы развития АПК региона. 2015. Т. 22. № 2 (22). С. 93-99.

51. Влияние послеуборочной обработки препаратом smartfresh на сохранение качества винограда / Т.Г. Причко [и др.] // Проблемы развития АПК региона. 2014. T. 19. № 3 (19). С. 75-80.

52. Салманов М.М., Исригова Т.А. Технологическая оценка винограда, выращенного в укрывной зоне виноградарства // Известия высших учебных заведений. Пищевая технология. 2004. № 1 (278). С. 54-55.

53. Влияние экологических условий и сортовых особенностей на химикотехнологические свойства и качество ягодных культур / Т.А. Исригова [и др.] // Известия Дагестанского ГАУ: электронный научный политематический сетевой журнал. 2020. № 1(5). С. 55-59.

54. Агробиологическая и химико-технологическая оценка столовых сортов винограда в условиях укрывной зоны Дагестана / Т.А. Исригова [и др.] // Известия Дагестанского ГАУ: электронный научный политематический сетевой журнал. 2020. № 1(5). C. 59-63. 


\section{References}

1. Amanov M.V. Dikorastushchij vinograd Azerbajdzhana // Politematicheskij setevoj elektronnyj nauchnyj zhurnal Kubanskogo gosudarstvennogo agrarnogo universiteta (Nauchnyj zhurnal KubGAU) [Elektronnyj resurs]. 2006. №02(18). S. 152-161. Shifr Informregistra: 0420600012\10034. Rezhim dostupa: http://ej.kubagro.ru/2006/02/pdf/16.pdf, 0,625 u.p.1.

2. Prilipko L.I. Vinogradovye - Vitaceae Lindl. Flora Azerbajdzhana. T. 6. Baku, 1955. S. 203-208.

3. Sosnovskij D.N. Vinogradovye - Vitaceae Juss. Flora SSSR. T. 14. M.; L., 1949. S. 674-710.

4. Alleweldt G., Spiegel-Roy P., Reisch B.: Grapes (Vitis). Genetic resources of temperate fruit and nut crops // Edited by: Moore J.N., Ballington J.R. Acta Hort. 1990. Vol. 290. P. 291-337.

5. Anzani R., Failla O., Scienza A., De Micheli L. Individuazione e conservazione del germoplasma di vite selvatica (Vitis vinifera sylvestris) in Italia // Vignevini. 1993. Vol. 6. P. 51-61.

6. Arnold C. Ecologie de la vigne sauvage, Vitis vinifera L. ssp. sylvestris (Gmelin) Hegi, dans les forêts alluvoales et colluviales dËurope // Geobotanica Helvetica. Academie Suisse des Sciences Naturelles. 2002.

7. Arnold C., Gillet F., Gobat J.M. Situation de la vigne sauvage Vitis vinifera ssp. sylvestris en Europe. Vitis. // 1998. № 41. P. 159-170.

8. Arroyo-garcìa R., Ruiz-garcìa L. Bolling L., Ocete L., Lòpez M. A., Arnold C., Ergul A. Multiple origins of cultivated grapevine (Vitis vinifera L. ssp. sativa) based on chloroplast DNA polymorphisms // Molecular Ecology. 2006. №15. P. 3707-3714.

9. Bacilieri R., Lacombe T., Le Cunff F., Di Vecchi-staraz M., Laucou V., Genna B., Peros J. P., This P., Boursiquot J. M. Genetic structure in cultivated grapevines is linked to geography and human selection. BMC Plant Biology. 2013. Vol. 13. P. 25.

10. Barrett H.C., Cramer S.G., Rhodes A.M. A taximetric study of interspecific variation in Vitis // Vitis. 1969. № 8. P. 177-187.

11. Bowen G.J., Beerling D.J., Koch P.L., Zachos J.C., Quattlebaum T. A humid climate state during the Palaeocene / Eocene thermal maximum // Nature. 2004. Vol. 432. P. 495-499.

12. Brizicky G. K. The genera of Vitaceae in the southeastern United States // Journal of the Arnold Arboretum. 1965. 4.

13. Brown R.W. Paleocene flora of the Rocky Mountains and Great Plains // US Geol Surv Prof Pap. 1962. Vol. 375. P. 1-120.

14. Comeaux B.L. Taxonomic studies on certain native grapes of the Eastern United States. PhD thesis. North Carolina State University: Department of Horticultural Science. 1984.

15. Comeaux B.L., Nesbitt W.B., Fantz P.R. Taxonomy of the native grapes of North Carolina // Castanea. 1987. Vol. 52: 197-215.

16. Cunha J., Baleiras-Couto M., Cunha J. P., Banza J., Soveral A. Carneiro L. C., Eiras-Dias J. E. Characterization of Portuguese populations of Vitis vinifera L. ssp. sylvestris (Gmelin) Hegi // Genet. Resour. Crop. Evol. 2007. Vol. 54. P. 981-988.

17. Di Vecchi-Staraz M., Laucou V., Bruno G., Lacombe T., Gerber S., Bourse T, et al. Low level of pollen-mediated gene flow from cultivated to wild grapevine: consequences for the evolution of the endangered subspecies Vitis vinifera L. ssp. sylvestris // J Hered. 2009. Vol. 100. P. 66-75.

18. Fregoni M. Viticoltura di Qualità - Trattato dell'eccellenza da terroir. III edizione. Ed. Tecniche nuove. 2013. 
19. Grassi F., De Mattia F., Zecca G., Sala F., Labra M. Historical isolation and Quaternary range expansion of divergent lineages in wild grapevine // Biol J Linn Soc. 2008. Vol. 95. P. 611-616.

20. Grassi F., Labra M., Imazio S., Spada A., Sgorbati S., Scienza A., Sala F. Evidence of a secondary grapevine domestication centre detected by SSR analysis // Theoretical and Applied Genetics. 2003. Vol. 107. P. 1315-1320.

21. Levadoux L. Les populations sauvages de Vitis vinifera L. // Ann. Amel. Plantes. 1956. Vol. 6. P. 59-118.

22. Lopes M.S., Mendonca D., Rodrigues dos Santos J.E., Eiras-Dias J.E, Da Camara Machado A. New insights on the genetic basis of Portuguese grapevine and on grapevine domestication // Genome. 2009. Vol. 52. P. 790-800.

23. Mai D.H. Neue früchte und samen aus Paläozänen ablagerungen Mitteleuropas // Feddes Repertorium. 1987. Vol. 98. P. 197-229.

24. Manchester S.R. Biogeographical relationships of North American Tertiary floras // Ann Missouri Bot Gard. 1999. Vol. 86. P. 472-522.

25. Mc Govern P.E. Ancient wine: The search of the origin of the viniculture. Princeton Univ. Press. 2003.

26. Miller N.F. Sweeter than wine? The use of the grapevine in early western Asia. Antiquity. 2008. Vol. 82. P. 937-946.

27. Mozaffarian V. Trees and shrubs of Iran. Farhang Moaser Publishers, Tehran. 2005. 1054 p.

28. Mullins M.G., Bouquet A., Williams L.E. The grapevine and its relatives. Biology of the grapevine. Edited by: Mullins MG, Bouquet A, Williams LE. Cambridge: Cambridge University Press. 1992. P. 17-36.

29. Myles S., Boyko A.R., Owens C., Brown P.J., Grassi F., Aradhya M.K., Prins B., Reynolds A., Chia J-M., Ware D., Bustamante C.D., Buckler E.S. Genetic structure and domestication history of the grape // Proc Natl Acad Sci. 2011. Vol. 108. P. 3530-3535.

30. Nie Z-L., Sun H., Chen Z-D., Meng Y., Manchester S.R., Wen J. Molecular phylogeny and biogeographic diversification of Parthenocissus (Vitaceae) disjunct between Asia and North America. Am J Bot. 2010. 97. P. 1342-1353.

31. Nie Z-L., Sun H., Manchester S.R., Meng Y., Luke Q., Wen J. Evolution of the intercontinental disjunctions in six continents in the Ampelopsis clade of the grape family (Vitaceae). BMC Evol Biol. 2012. P. 212.

32. Osete R., Ocete R., Ocete C., Angeles Perez Izquierdo M., Rustioni L., Failla O., Chipashvili R., Maghradze D. Ecological and sanitary characteristics of the Eurasian wild grapevine (Vitis vinifera L. ssp. sylvestris (Gmelin) Hegi) in Georgia (Caucasian region) // Plant Genetic Resources: Characterisation and Utilisation. 2012. Vol. 10. Issue 2. P. 155-162.

33. Péros J-P., Berger G., Portemont A., Boursiquot J-M., Lacomb T. (2011) Ge-netic variation and biogeography of the disjunct Vitis subg. Vitis (Vitaceae) // J Biogeogr. 2011. Vol. 38. P. 471-486.

34. Press F., Siever R. New York: W.H. Freeman and Company. 1985. 4

35. Reisch B.I., Pratt C. Grapes. Fruit breeding. Edited by: Janick J, Moore JN. New York: Wiley. 1996. P. 297-369.

36. Rogers D.J., Rogers C.F. Systematics of North American grape species // Am J Enol Vitic. 1978. Vol. 29. P. 73-78.

37. Sabeti H. Forests, trees, and shrubs of Iran, vol 13. University of Yazd Press, Yazd. 1976. P. 1-886 (in Persian).

38. Sefc K. M., Steinkellner H., Lefort F., Botta R., Camara Machado A., Borrego J., Maleti E., Glossl J. Evaluation of the genetic contribution of local wild vines to European germplasm // Am. J. Enol. Vitic. 2003. Vol. 54. P. 15-21. 
39. This P., Lacombe T., Thomas M.R. Historical origins and genetic diversity of wine grapevines // Trends Genet. 2006. Vol. 22. P. 511-519.

40. Tiffney B.H., Manchester S.R. The use of geological and paleontological evidence in evaluating plant phylogeographic hypotheses in the northern hemisphere Tertiary // Int J Plant Sci. 2001. Vol. 162 (Suppl 6). P. 3-17.

41. Vassilczenko L.T. Vitaceae. In: Rechinger KH (ed) Flora Iranica, vol 74. Academische Druck Verlagsanstalt, Graz. 1970. P. 1-5 (in Persian).

42. Xiang Q-Y., Soltis D.E., Soltis P.S. The Eastern Asian and Eastern and Western North American floristic disjunction: congruent phylogenetic patterns in seven diverse genera // Mol Phylogenet Evol. 1998. Vol. 10. P. 178-190.

43. Zecca G., Abbott J.R., Sun W.B., Spada A., Sala F., Grassi F. The timing and the mode of evolution of wild grapevines (Vitis). Mol Phylogenet Evol. 2012. Vol. 62. P. 736-747.

44. Zecca G., De Mattia F., Lovicu G., Labra M., Sala F., Grassi F. Wild grapevine: silvestris, hybrids or cultivars that escape from vineyards? Molecular evidence in Sardinia // Plant Biology. 2010. Vol. 12. P. 558-562.

45. Zohary D. Domestication of the grapevine Vitis vinifera L. in the Near East. In: Mc Govern P. E. (Ed.), The Origins and Ancient History of Wine. Gordon and Breach, Philadelphia. 1995. P. 23-30.

46. $\mathrm{https}: / / \mathrm{www}$. ipni.org/n/69086-1

47. http://www.theplantlist.org/tpl1.1/record/kew-2456987

48. Isrigova T.A., Musaeva N.M., Salmanov M.M. Biologicheski aktivnye dobavki iz semyan, kozhicy i grebnej vinograda // Problemy razvitiya APK regiona. 2012. T. 10. № 2 (10). S. 113-119.

49. Sposob konservirovaniya plodov i yagod: patent na izobretenie RUS 2347505 / Isrigova T.A., Salmanov M.M.; zayavl.13.08.2007, opubl. 2009-02-27.

50. Isrigova T.A., Salmanov M.M., Bagavdinova L.B. Proizvodstvo funkcional'nyh bezalkogol'nyh napitkov na osnove vinograda // Problemy razvitiya APK regiona. 2015. T. 22. № 2 (22). S. 93-99.

51. Vliyanie posleuborochnoj obrabotki preparatom smartfresh na sohranenie kachestva vinograda / T.G. Prichko [i dr.] // Problemy razvitiya APK regiona. 2014. T. 19. № 3 (19). S. 75-80.

52. Salmanov M.M., Isrigova T.A. Tekhnologicheskaya ocenka vinograda, vyrashchennogo v ukryvnoj zone vinogradarstva // Izvestiya vysshih uchebnyh zavedenij. Pishchevaya tekhnologiya. 2004. № 1 (278). S. 54-55.

53. Vliyanie ekologicheskih uslovij i sortovyh osobennostej na himikotekhnologicheskie svojstva i kachestvo yagodnyh kul'tur / T.A. Isrigova [i dr.] // Izvestiya Dagestanskogo GAU: elektronnyj nauchnyj politematicheskij setevoj zhurnal. 2020. № 1(5). S. 55-59.

54. Agrobiologicheskaya i himiko-tekhnologicheskaya ocenka stolovyh sortov vinograda v usloviyah ukryvnoj zony Dagestana / T.A. Isrigova [i dr.] // Izvestiya Dagestanskogo GAU: elektronnyj nauchnyj politematicheskij setevoj zhurnal. 2020. № 1(5). S. 59-63. 